\title{
Reforma policial: Aproximación a la supervisión ciudadana de las policías en Estados Unidos
}

\author{
Police reform: An approach to citizen oversight of policing in the United States
}

\author{
Víctor Beltrán Román \\ Boise State University, Estados Unidos
}

\begin{abstract}
RESUMEN En Estados Unidos, la supervisión ciudadana se ha convertido en una manera legítima de hacer que las policías rindan cuenta de sus actos. Así, cada vez que los departamentos de policía han enfrentado una crisis de legitimidad y pérdida de confianza por parte de la ciudadanía a partir de escándalos de mala conducta policial, las autoridades han tomado medidas tendientes a mejorar los mecanismos de responsabilización. Entre las posibles soluciones, la creación de organismos de control ciudadano se ha vuelto la más usual. El objetivo de este artículo es entregar información y reflexiones que ayuden a alimentar el debate en torno a la reforma policial en Chile. Para esto, el documento conceptualiza la supervisión ciudadana y presenta los escenarios que usualmente han derivado en la implementación de estos mecanismos en Estados Unidos. Además, en este trabajo se presentan y describen algunos modelos de supervisión disponibles en el sistema estadounidense.
\end{abstract}

PALABRAS CLAVE Reforma policial, responsabilidad policial, supervisión civil, función policial, control ciudadano.

ABSTRACT Civilian oversight has emerged as one of the legitimate means to enforce police accountability in the United States. Thus, every time the police face legitimacy issues and loss of trust of the citizens as a result of police misconduct scandals, the response has been to improve the mechanisms of police accountability through the creation of civilian oversight bodies. This paper aims to provide information and analysis that might be useful to feed the debate on police reform in Chile. To achieve this goal, the documents presents a general overview of the concept of civilian oversight and reviews the scenarios that have led to the creation of oversight agencies. Then, some mechanisms instituted in the U.S. legal system are presented and described.

KEYWORDS Police reform, police accountability, civilian oversight, policing, citizen control. 


\section{Introducción}

La función de las policías en las sociedades modernas es increíblemente compleja, ya que en ellas se confía una gran cantidad de responsabilidades, todas de muy diversa naturaleza (Goldstein, 1977: 21). ${ }^{1}$ Aunque intuitivamente se piensa que las policías, como actores del sistema de justicia criminal, únicamente desarrollan actividades vinculadas a la investigación de delitos y prevención de la criminalidad, lo cierto es que destinan parte importante de su tiempo a actividades no relacionadas con ello. Las policías atienden emergencias de personas intoxicadas, crisis de salud mental, situaciones relacionadas con personas extraviadas, problemas de ruidos molestos, conflictos entre vecinos o familiares, control de movimiento de vehículos y personas, accidentes de tránsito, infracciones de tránsito, etcétera (Goldstein, 1977: 25). Todo lo anterior transforma a la función policial en un trabajo difícil.

Las policías, al desarrollar sus funciones en tanto agentes del Estado, están entregando una suerte de servicio a la ciudadanía, ya que no solo deben asegurar los derechos individuales y las libertades de las personas, sino también velar por la vigencia del Estado de derecho (Sen, 2010: 8). ${ }^{2}$ Así, para cumplir con sus funciones, las policías gozan de ciertas potestades que muchas veces pueden incomodar a los ciudadanos, ya que ostentan el monopolio legítimo del uso de la fuerza (Sen, 2010: 165). En la práctica, esto se traduce en la posibilidad de detener personas y vehículos, llevar a cabo actividades de vigilancia o intrusivas, realizar controles de identidad, interrogar víctimas, testigos o imputados, registrar individuos y vehículos, incautar objetos, arrestar, etcétera.

Debido a la función que desarrollan y los poderes que ostentan, las policías están mucho más expuestas a cometer abusos por el mal uso de ellos (Miller, 2002: 3), ya que están en una suerte de vitrina dentro del Estado de derecho. Así las cosas, para desarrollar sus funciones de manera apropiada y en armonía con el bien común, las policías deben mantener el equilibrio entre trabajar dentro de los principios y valores de una sociedad libre y democrática y, al mismo tiempo, proveer sus servicios de manera eficiente a la comunidad (Goldstein, 1977: 307).

Cuando la policía no ejercita apropiadamente sus poderes, surgen los problemas de mala conducta policial. Es ahí cuando hacerla responsable por sus actos se transforma

1. Aunque se trata de una publicación de 1977, la obra del profesor Goldstein sigue más vigente que nunca. Durante mi investigación sobre el proceso de reforma del Departamento de Policía de la ciudad de Madison, Wisconsin, pude conocer su gran obra. El autor se dedicó a desarrollar un modelo eficaz de policía que mantuviese el respeto por los valores democráticos y a explorar el ejercicio de la discreción policial, la responsabilidad política de las policías, etcétera. A raíz de su muerte en marzo de 2020, me permito dedicar a su memoria las primeras líneas de esta humilde contribución al estudio de la responsabilización policial. No me cabe duda de que el legado del profesor permanecerá por muchos años, ya que el mundo académico lo describe como un gran estudioso de la función policial y como un líder en reformas policiales por sus contribuciones invaluables en estrategias modernas de policing. Sobre su trayectoria, véase Mazerrolle (2020: 349-354).

2. En el caso de Chile, por ejemplo, de acuerdo con el artículo 101 de la Constitución Política, Carabineros e Investigaciones existen para dar eficacia al derecho, garantizar el orden público y la seguridad publica. 
en un desafío. En dicho contexto, surgen los mecanismos de control y responsabilización policial o police accountability, ${ }^{3}$ con el objetivo de asegurar el ejercicio apropiado de los poderes policiales y, en caso de que esto no ocurra, hacerlos responsables por sus actos (United Nations Office on Drugs and Crime, 2011: 5). Entre los diversos mecanismos para enfrentar el desafío de la responsabilización policial, las agencias de supervisión civil o civilian oversight han surgido como las más usuales en Estados Unidos (Sen, 2010: 5 y 138; De Angelis y otros, 2016: 3 ). ${ }^{4}$ Es importante mencionar que al hablar de civilian oversight no nos estamos refiriendo específicamente a cualquier tipo de supervisión o control civil, sino a auténticos organismos de control ciudadano, en los que la propia comunidad supervigila diversos aspectos del ejercicio de la función policial, la adopción de protocolos, los procedimientos investigativos internos, el uso de recursos, los procedimientos adjudicativos e imposición de medidas disciplinarias y la trasparencia, entre otros aspectos. ${ }^{5}$

Actualmente, la organización National Association for Civilian Oversight of Law Enforcement (NACOLE) ${ }^{6}$ registra poco más de 120 oficinas de police oversight en los Estados Unidos. ${ }^{7}$ Las razones para brindar este tipo de respuestas son más bien sencillas.

3. No existe una traducción exacta al español que capture la riqueza y complejidad de los términos accountability o police accountability. Sin embargo, algunos autores presentan la traducción como «rendición de cuentas», «responsabilidad»y «responsabilización». Sobre esto último, véase Mawby y Wright (2005: 902). Para profundizar sobre el concepto, véase Reiner (1993: 1-23) y Brodeur (1999: 125-164).

4. Por ejemplo, a propósito del estallido de protestas que surgió en Estados Unidos luego de la muerte del ciudadano afroamericano George Floyd en Minnesota, una de las promesas del candidato presidencial Joe Biden fue la creación de una comisión nacional de supervisión civil. Este debate también se instaló en Kenosha, Wisconsin, luego de que el ciudadano afroamericano Jacob Blake recibiera siete disparos por parte de un policía. Así, Kenosha centró su mirada en la situación que actualmente se vive en Madison, ciudad del mismo Estado, donde se está implementación un mecanismo de civilian oversight.

5. En general, la literatura norteamericana utiliza el término civilian oversight para referirse a mecanismos de control en los cuales la comunidad se encarga de hacer efectiva la responsabilización policial. Sin embargo, si se efectúa una traducción literal del término a supervisión civil, esto puede evocar erróneamente la idea de un simple sometimiento a la autoridad civil como un Ministerio del Interior. Para efectos de este trabajo, debe entenderse civilian oversight o supervisión civil en referencia a entidades compuestas de ciudadanos encargados de la responsabilización de los departamentos de policía que supervigilan. Por esto, se utilizarán indistintamente los siguientes términos: supervisión civil, control ciudadano, supervisión ciudadana, civilian oversight, citizen oversight y citizen control.

6. Su misión es crear una comunidad de apoyo para entidades independientes de supervisión civil que busquen hacer que sus agencias policiales sean más transparentes, responsables y que respondan a las comunidades que sirven. Para más información, véase «Mission, vision y values», NACOLE, 2020, disponible en bit.ly/31TPlO8.

7. Para más información, véase «Police Oversight Worldwide», NACOLE, 2020, disponible en bit. ly/3201S2J. NACOLE registra oficinas de police oversight en otras partes del mundo, como Austria, Bélgica, Canadá, Hong Kong, Irlanda, Israel, Jamaica, Nueva Zelanda, Sudáfrica, Reino Unido, entre otros. Con todo, debe tenerse presente que no todas las oficinas de oversight se encuentran publicadas bajo esta organización. Un caso cercano es Brasil, que cuenta con la Oficina del Defensor del Pueblo o Police Ombudsmen's Office. Para más información, véase «Police Oversight by Jurisdiction (USA)», NACOLE, 2020, disponible en bit.ly/2TGl2pO. 
La creación de agencias de supervisión siempre tiene como antecedentes graves escándalos de mala conducta policial. En este escenario, las policías se ven en la necesidad de recuperar su autoridad moral, su integridad y la confianza de la ciudadanía, con el fin de poder cumplir con sus funciones en base a la legitimidad en lugar de la fuerza. ${ }^{8}$ En definitiva, cada vez que el desempeño de la policía se ve cuestionado, su legitimidad decrece y las reformas se vuelven necesarias (United Nations Office on Drugs and Crime, 2011: 4-5).

Este trabajo tiene como objetivo introducir el concepto de supervisión civil y entregar una visión general de los principales modelos de civilian oversight existentes. ${ }^{9}$ En cuanto a su estructura, la primera parte de este trabajo contextualiza y justifica los motivos por los que debe interesarnos esta materia en relación con la situación chilena. La segunda parte entrega una visión general de la supervisión civil, explicando las principales necesidades que han llevado a la adopción de estos mecanismos. Por último, la tercera parte presenta y describe las principales características de algunos modelos concretos de supervisión civil de Estados Unidos.

\section{¿Por qué debe interesarnos la supervisión civil en Chile?}

Las democracias tienen la expectativa legítima de que sus policías se desempeñen bajo los más altos estándares, es decir, que los agentes policiales no cometan delitos, infracciones reglamentarias ni tampoco daños de naturaleza civil en el desempeño de sus funciones (Roach, 2014: 29). Ahora, si lo anterior no ocurre, las democracias deben contar con mecanismos de police accountability para hacer responsable a la policía por sus acciones, ya que, de lo contrario, estas democracias terminarán convirtiéndose en un Estado policial, en el que la estabilidad del Estado de derecho se verá desafiada por la impunidad de los propios poderes coercitivos del Estado (Roach, 2014: 29; Mawby y Wright, 2005: 907).

En Chile, las Fuerzas de Orden y Seguridad Pública han visto dañada su imagen en los últimos años. ${ }^{10}$ Particularmente, con respecto a Carabineros de Chile, la confianza

8. Al respecto, Murphy y otros (2008: 137) señalan que el derecho de una institución legítima a que sus reglas y decisiones sean obedecidas es un derecho conferido por el público, es decir, no descansa en el poder de la institución para imponer sus reglas. En cuanto al concepto de legitimidad policial en particular, véase Bottoms y Tankebe (2012: 124-126). También véase Pascual Cortés, «El problema de una policía militarizada», Ciper Chile, 12 de junio de 2020, disponible en bit.ly/2JjUeK1, quien señala que «un Estado que cree que expandiendo su poder de reacción reafirma su autoridad en realidad no hace más que evidenciar e institucionalizar su incapacidad para asegurar condiciones normales de convivencia política».

9. Con el fin de aproximarse al objeto de estudio, la metodología de este trabajo se basa en una revisión de la literatura disponible sobre civilian oversight en Estados Unidos. Asimismo, se recopilaron materiales relativos a modelos específicos de civilian oversight implementados en algunas ciudades de Estados Unidos, los cuales son presentados de manera descriptiva en la tercera parte de este trabajo. De esta manera, con el fin de entregar una visión general de los mismos, se presentan los principales aspectos de estos mecanismos, describiendo su conformación, atribuciones, deberes y responsabilidades, entre otros aspectos de interés.

10. En esos términos lo reconoce el Boletín 12.250-25 sobre el proyecto de ley que moderniza la gestión 
en la institución ha disminuido significativamente y de manera sostenida desde agosto de 2015 hasta diciembre de 2019, pasando de 57 a 17 puntos de aprobación (Centro de Estudios Públicos, 2019: 16). Un reciente estudio con datos de julio de 2020 confirma la tendencia a la baja, lo que da cuenta de una pérdida sostenida de confianza y legitimidad policial."

Así, desde hace un tiempo, entre los expertos se habla de una crisis de legitimidad, caracterizada por la pérdida de credibilidad y confianza en amplios sectores de la población. Aunque se trata de un problema antiguo, este se habría agudizado a propósito de la crisis social de octubre de 2019 (Comisión para la Reforma, 2020: 9; Duce y Dammert, 2019: 1). Esta crisis no solo estaría explicada por la existencia de una percepción generalizada de que el desempeño en la función policial es deficiente (Fundación Paz Ciudadana, 2019: 26-31), ${ }^{12}$ sino también por aspectos culturales y organizacionales que vuelven a la institución excesivamente burocrática, sin espacios para la innovación y, además, lejana a la ciudadanía (Comisión para la Reforma, 2020: 9). Lo anterior, se suma a escándalos de mala conducta policial, casos de violaciones a los derechos humanos, fraudes financieros, fabricación de evidencias y uso excesivo de la fuerza, entre los cuales destacan los casos Operación Huracán, Catrillanca y Megafraude en Carabineros (Dammert, 2020: 7-8).

Si se atiende a lo estrictamente normativo, existen aspectos que preocupan. Así, particularmente Carabineros, como advierten Pablo Contreras, Ricardo Montero y Sebastián Salazar en lo que denominan autonomía normativa, puede dictar para sí y en forma autónoma normas reglamentarias, en algunos casos sin que se requiera la firma del Ministerio del cual dependen. ${ }^{13}$ Asimismo, en la institución existe un régimen jurídico diferenciado del resto de la administración del Estado, con protecciones de nivel constitucional y que, en definitiva, le permiten mantenerse al margen del control efectivo de las autoridades civiles y del escrutinio de la ciudadanía, con nula o escasa rendición de cuentas (Contreras y otros, 2020a: 241-247; Duce y Dammert, 2019: 1). ${ }^{14}$

Con todo, existen diversas instituciones que, desde sus ámbitos de competencia y dentro de sus atribuciones, efectúan alguna clase de control de las policías. En primer lugar, desde un punto de vista orgánico, las policías dependen jerárquicamente

institucional y fortalece tanto la probidad como la transparencia en las Fuerzas de Orden y Seguridad Pública. Para más información, véase «Boletín 12.250-25 - Moderniza la gestión institucional y fortalece la probidad y la transparencia en las Fuerzas de Orden y Seguridad Pública», Senado de la República de Chile, 2020, disponible en bit.ly/31Xe18l.

11. Para más información, véase «Legitimidad de Carabineros no repunta: Estudio de Chile 21 refleja pérdida sostenida en la confianza policial con un 61\% de rechazo», Monitor de Seguridad, 4 de agosto de 2020, disponible en bit.ly/3mE4sDq.

12. Para más información, véase nota anterior.

13. Para más información, véase Pablo Contreras, Ricardo Montero y Sebastián Salazar, «Carabineros: Una institución que (legalmente) se manda sola», Ciper Chile, 30 de enero de 2020, disponible en bit. ly/2TFHwa8.

14. Para más información, véase nota anterior. 
del Ministerio del Interior y Seguridad Pública. ${ }^{15}$ En segundo lugar, aunque resistido y discutido en estas últimas semanas, las policías están sometidas a la fiscalización de la Contraloría General de la República. ${ }^{16}$ En tercer lugar, el Consejo para la Transparencia no solo fiscaliza el cumplimiento de las normas de transparencia activa de la institución, sino también que den estricto cumplimiento a las solicitudes de acceso a la información pública intentadas por la ciudadanía u ordenadas mediante resolución firme (Ley 20.285, 2008: artículos 45 a 49). ${ }^{17}$ Por último, se encuentra el Instituto Nacional de Derechos Humanos, que se encarga de fiscalizar el trabajo policial mediante observaciones, además de contar con la facultad de ejercer acciones legales en el ámbito de su competencia (Ley 20.405, 2009: artículos 2 y 3). Ahora, a pesar de tratarse de mecanismos externos de responsabilización o accountability, para efectos de este trabajo ninguno califica como un auténtico mecanismo de civilian oversight en el sentido que se ha planteado. ${ }^{18}$

En fin, aunque han existido intentos de reforma e incluso se ha hablado de refundación, nada de eso ha llegado a materializarse. ${ }^{19}$ En general, las medidas propuestas han sido tendiendes a mejorar la gestión, tanto de recursos humanos como económicos, pero lo que en realidad se requiere son medidas que hagan frente a problemas mucho más trascendentales y estructurales, ya que, actualmente, Chile cuenta con una policía

15. Anteriormente, Carabineros de Chile dependía del Ministerio de Defensa Nacional. Esto se modificó mediante la Ley 20.502 del 9 de febrero de 2011, que creó el Ministerio del Interior y Seguridad Pública. Para más información, véase el actual texto del artículo 101 de la Constitución Política de la República, que en su inciso 2 menciona que Carabineros e Investigaciones son instituciones dependientes del Ministerio del Interior y de Seguridad Pública.

16. Aunque se ha argumentado la falta de competencia de Contraloría para fiscalizar a Carabineros (por tratarse de cuestiones de mérito y no de legalidad), la primera encontraría su fundamento para ejercer su rol fiscalizador sobre Carabineros en el artículo 98 de la Constitución Política, que le encarga el control de la legalidad de los actos y de la administración, y en el artículo 133 de la Ley 10.336 sobre organización y atribuciones de la Contraloría General de la República, que entrega al contralor o cualquier otro funcionario de la Contraloría especialmente facultado por aquel, la facultad de ordenar, cuando lo estime necesario, la instrucción de sumarios administrativos. Además, esta facultad se encuentra regulada en la Resolución 510 del 10 de octubre de 2013 de la Contraloría General de la República.

17. Véase en cuanto a las potestades del Consejo para la Transparencia para establecer sanciones en casos de incumplimiento injustificado de las normas de transparencia activa, casos de denegación infundada de acceso a la información y casos de no entrega oportuna de información en la forma ordenada.

18. En lo que dice relación con las características de una supervisión policial efectiva, véase «What are the features of an effective police oversight body?», NACOLE, 2020, disponible en bit.ly/2TDuzxL.

19. Los principales corresponden al Boletín 12.699-07, que corresponde al proyecto de ley de especialización preferente de las policías que surgió luego del Acuerdo Nacional por la Seguridad Pública en julio de 2018; y el Boletín 12.1250-25, que moderniza la gestión institucional y fortalece tanto la probidad como la transparencia en las Fuerzas de Orden y Seguridad Pública. También existen esfuerzos anteriores y posteriores, pero ninguno de ellos ha visto la luz hasta ahora. El detalle de los proyectos de ley sobre modernización de las policías se puede ver en «Conozca detalles de «Hoja de Ruta Legislativa para la Modernización Policial», Senado de la República de Chile, 26 de enero de 2019, disponible en bit.ly/35PbJto. 
que enfrenta una profunda crisis institucional, deslegitimada y con altos niveles de desconfianza por parte de la ciudadanía. Ante esto, la supervisión civil o el control ciudadano pueden ofrecer alternativas interesantes.

\section{Algunos matices}

En este punto, es importante tener en cuenta ciertas prevenciones o limitaciones de este trabajo. En primer lugar, este artículo no pretende construir un modelo de supervisión civil para Chile, ni tampoco proponer la adopción de un modelo ya existente en Estados Unidos. En efecto, no existe certeza de si los métodos adoptados en otros sistemas legales pueden ser trasplantados - sin más - a otras democracias. Esto se debe a que los mecanismos se construyen a la medida, de acuerdo con las necesidades de cada jurisdicción. Sin embargo, las ideas subyacentes a estos mecanismos de responsabilización policial indican que podrían ser modelos adecuados, ya que no solo enfatizan principios como la separación de poderes, sino también como la existencia de pesos y contrapesos para asegurar legitimidad, efectividad y transparencia en la actividad policial (Mawby y Wright, 2005: 901, 908).

En segundo lugar, tampoco se quiere argumentar que un mecanismo de civilian oversight acabaría con todos los problemas que actualmente afectan a la policía chilena o que la adopción de alguno de dichos mecanismos es la forma adecuada de abordar la cuestión de la reforma policial.

Por el contrario, las pretensiones de este trabajo son mucho más moderadas y austeras. De hecho, guardan relación únicamente con enriquecer el debate en torno a la reforma policial mediante la revisión y descripción de la experiencia estadounidense a través de la creación e implementación de entidades de supervisión ciudadana considerando especialmente que, ante escenarios más o menos similares a los que se viven actualmente en Chile, se han tomado medidas como las que se describirán en este trabajo.

En tercer lugar, pese a que se trate de escenarios fácticos similares, deben considerarse las diferencias organizacionales entre Chile y Estados Unidos, tanto a nivel político como policial. Naturalmente, Estados Unidos responde a la lógica de un Estado federal, donde existen policías federales (como el FBI o la DEA), policías estatales o de caminos, policías de condado y policías municipales, además de algunas policías tribales. Por su parte, Chile, en la lógica de un Estado unitario, encarga las labores de orden y seguridad pública para todo el territorio nacional a Carabineros e Investigaciones. Por lo demás, existen otras diferencias históricas, culturales, de formación y de prioridades en la vigilancia, entre otras.

Sin perjuicio de lo anterior, el escenario fáctico que actualmente enfrentan las policías en Chile (especialmente Carabineros) no presenta diferencias sustanciales con lo que ha ocurrido en Estados Unidos cuando sus policías han enfrentado crisis de control y legitimidad. En dichos casos, la respuesta de las autoridades ha sido clara, adoptando mecanismos de civilian oversight en sus diversas variantes (President's Task 
Force on 21st Century Policing, 2015: 26-27). ${ }^{20}$ Por lo anterior, aunque se se trata de instituciones más bien ajenas a nuestra tradición jurídica, ${ }^{21}$ es importante ampliar la mirada y tener presente este tipo de soluciones, que eventualmente podrían ser útiles y ayudar a lidiar de mejor manera con los problemas que enfrentan las Fuerzas de Orden y Seguridad en Chile.

\section{Civilian Oversight: Generalidades}

En una sociedad democrática, las policías deben responder ante la ciudadanía. Es decir, estas deben aceptar ser cuestionadas sobre sus decisiones, acciones o conductas y aceptar las consecuencias (Walker, 2014: 8; Schedler, 1999: 13-28; Mawby y Wright, 2005: 907). En general, el término police accountability describe un sistema complejo de chequeos y balances internos y externos, destinados a asegurar que la policía llevará adelante sus deberes de manera tanto apropiada como justificada y que, de no hacerlo, serán responsables por ello, sea a nivel institucional o individual (United Nations Office on Drugs and Crime, 2011: 6).

Luego, existen diversos tipos de mecanismos de police accountability, tanto a nivel interno como externo. A nivel interno, por su puesto y rango, las policías son responsables ante sus superiores en la propia institución. A nivel externo, usualmente responden ante una autoridad civil como un ministro del interior o primer ministro, así como ante el poder judicial y legislativo. Luego, existen otros mecanismos externos, como instituciones que velan por los derechos humanos, entidades de supervisión civil, etcétera. En algunos casos, existe también accountability internacional a través de organismos internacionales que velan por el respeto a los derechos humanos (United Nations Office on Drugs and Crime, 2011: 12-14). Este trabajo se enfocará únicamente en las entidades de supervisión civil o de control ciudadano.

Dicho lo anterior, entre los distintos mecanismos de accountability, la supervisión civil ha surgido como una forma legítima y usual de hacer efectiva la responsabilidad policial (Sen, 2010: 5 y 138; De Angelis y otros, 2016: 8). Aunque a veces se le denomina civilian oversight, «supervisión ciudadana», «revisión ciudadana», «revisión externa» o «comité de revisión civil» (Dempsey y Forst, 2013: 247-248), lo cierto es que todos estos conceptos abarcan la idea de cualquier entidad o procedimiento que involucre a personas externas a la institución policial, quienes ostentan el rol de llamar a las policías a rendir cuenta de sus acciones, protocolos, políticas, organización y prioridades (Miller, 2002: 1; Phillips y Trone, 2002: 14; Walker, 2001). En definitiva, la supervisión civil se caracteriza por la existencia de una o más personas, externas a la cadena de mando de un departamento de policía, cuyo trabajo central es responsabilizar a dicho departamento, a sus oficiales y empleados (De Angelis y otros, 2016: 13).

En cuanto a los objetivos de la supervisión civil, la literatura ha señalado que serían

20. Para más información, véase la recomendación 2.8 .

21. Con respecto al modelo de policía comunitaria en América Latina, véase Frühling (2003: 12-28). 
comunes a todo mecanismo de supervisión los siguientes: mejorar la confianza de la ciudadanía, asegurar que los procedimientos de reclamo sean accesibles, promover investigaciones justas y minuciosas en casos de mala conducta policial desincentivando esta última e incrementar en simultáneo la transparencia de la institución (De Angelis y otros, 2016: 3; Stephens y otros, 2018: 20-21). ${ }^{22}$

La supervisión civil puede manifestarse a través de diferentes modelos. Existen modelos centrados en investigación caracterizados por llevar adelante investigaciones de forma independiente en ciertos tipos de reclamos y quejas. Otros, se enfocan en la revisión y se encargan de chequear investigaciones terminadas para establecer si fueron llevadas adelante de forma adecuada. Por otra parte, otros se enfocan en un monitor o auditor independiente, cuyo objetivo es promover cambios sistemáticos a gran escala en las instituciones policiales. Finalmente, existen modelos híbridos que comparten características de los demás modelos de supervisión. Sobre estos mecanismos se profundizará más adelante.

\section{Necesidad de supervisión civil: De la crisis al control}

En general, los mecanismos de supervisión civil surgen como una respuesta de parte de la ciudadanía a uno o más problemas vinculados al desempeño de las policías (Miller, 2002: 2; Sen, 2010: 142). ${ }^{23}$ De esta manera, cada uno de ellos ha sido creado y diseñado como una respuesta específica a necesidades clave dentro de una jurisdicción para resolver ciertos problemas vinculados a la función policial. ${ }^{24}$ Entonces, la pregunta de por qué surge o por qué se necesita la supervisión civil debe ser respondida caso a caso, con miras al problema que la ciudadanía desea resolver. A continuación, se presentarán brevemente los escenarios más comunes que han llevado a la creación de este tipo de entidades.

\section{La ciudadanía no está contenta con su policía}

Es el escenario más común que ha llevado a implementar controles civiles a las policías (Dempsey y Forst, 2013: 247-248). Incidentes de uso de fuerza letal o tensiones entre la policía y determinados segmentos de la comunidad han abierto la puerta a la creación de mecanismos de supervisión. Así, a raíz de escándalos de mala conducta policial, a

22. Conclusión en base a datos recolectados a partir de 97 programas de supervisión civil.

23. Por regla generalísima, la supervisión ha surgido como iniciativa de la ciudadanía. Sin embargo, un caso destacable es el ocurrido en 1974 en Chicago, cuando el propio Departamento de Policía tomó la iniciativa de crear la denominada Office of Professional Standards (OPS). Para más información, véase Miller (2002: 1).

24. Esta es la razón principal por la cual los mecanismos de oversight han adoptado formas tan diferentes en cuanto a sus roles, funciones, estructuras, poderes, etcétera. Así, las diferencias dependen del clima político que existía al momento de crear el organismo de supervisión. Para más información, véase Sen (2010: 150). 
los ojos de la ciudadanía la policía carece o pierde legitimidad y confianza (Murphy y otros, 2008: 136-155). Luego, cuando dichos incidentes ocurren a menudo y se transforman en un problema sistemático, la policía debe tomar medidas destinadas a ganar o recuperar autoridad moral, la integridad y la confianza de la ciudadanía. Para esto, mejorar las interacciones y la relación entre la policía y la comunidad es clave (Community Relations Service, 2005: 1)

Al mirar la experiencia estadounidense es sencillo encontrar casos de este tipo (Mawby y Wright, 2005: 902), ${ }^{25}$ especialmente porque el auge de la supervisión civil estuvo fuertemente influenciado por el movimiento por los derechos civiles (Walker, 2006: 1-10), además de la exposición de casos de corrupción, mala conducta y comisión de delitos por parte de oficiales de policía (Mugari, 2018: 1). En concreto, la historia del civilian oversight en Estados Unidos comenzó a escribirse en Filadelfia, cuando la policía fue acusada de prácticas discriminatorias en contra de ciertos segmentos de la población (Sen, 2010: 139). Así, se creó el denominado Police Advisory Board (PAB), un consejo compuesto de ciudadanos que se encargaban de recibir reclamos contra la policía, derivar los casos al departamento de policía para ser investigados y, luego, al analizar los resultados de la investigación, recomendaban alguna medida o acción que, finalmente, era decidida por el jefe de la institución (Attard y Olson, 2013: 2). ${ }^{26}$ En la actualidad, a casi 65 años de la creación del PAB, existen ciudades estadounidenses que recién están adoptando mecanismos de supervisión civil como respuesta a problemas sistemáticos de mala conducta policial, como el caso de Madison.

La confianza mutua entre la comunidad y la policía es clave para mantener la seguridad pública y una función policial efectiva, ya que la policía muchas veces confía en la cooperación de miembros de la comunidad para llevar adelante algunas de sus funciones, así como también los primeros van a confiar en los segundos en la medida en que sus acciones reflejen principios de justicia (Community Relations Service, 2005: 1).

\section{Problemas de accesibilidad a procedimientos de reclamo en contra de la policía}

En otros casos, la supervisión ciudadana ha surgido debido a problemas relacionados con la accesibilidad y efectividad de los mecanismos de reclamo en contra de la policía (Walker: 2001; Goldsmith y Lewis, 2000: 331). En dichos casos, la preocupación central del organismo de oversight ha sido el fenómeno de la «cifra negra», es decir,

25. No solo en Estados Unidos, sino también en Reino Unido la experiencia es similar. Así, en 1962 se creó la Royal Commission of the Police luego de una serie de escándalos policiales, plasmando nuevas disposiciones sobre rendición de cuentas, policías y sistemas de quejas.

26. Con todo, es posible encontrar esfuerzos anteriores por la creación de organismos de supervisión. Por ejemplo, en Los Ángeles (1925), Nueva York (1935) y Washington D.C. (1948). Sin embargo, todos esos intentos acabaron siendo poco efectivos, principalmente por ser organismos débiles, prácticamente sin facultades relevantes más que el poder recibir reclamos en contra de la policía. La opinión de Walker (2006: 3) es que la primera agencia genuina de civilian oversight fue la de Washington D.C., cuando en 1948 se creó el denominado Citizens Review Board (CRB) después de un estallido de protestas y tensiones raciales. 
aquellos reclamos en contra de la policía que no son reportados o registrados, lo que puede ocurrir porque la policía lo decide así o porque existen otras razones (costos no necesariamente económicos) que llevan a los ciudadanos a no reclamar. Por ejemplo, la conveniencia de hacer una denuncia, el temor de represalias o incluso, derechamente, la desinformación (Sen, 2010: 36). ${ }^{27}$

En cuanto a la accesibilidad a los procedimientos de reclamo, un problema se daría porque la estación de policías es el único lugar habilitado para recibirlos, lo que vuelve al procedimiento prácticamente inaccesible, ya sea porque el reclamante teme represalias o porque se establecen barreras de acceso al mismo por parte de la policía (Sen, 2010: 36; Beltrán, 2018). En definitiva, presentar una denuncia contra la policía en su propio recinto genera desincentivos para los reclamantes. En ese orden de ideas, la creación de agencias facultadas para recibir reclamos ayuda a dar mayor accesibilidad al procedimiento y, en general, a mejorar la satisfacción de la ciudadanía con el sistema.$^{28}$ Junto con ello, deben tomarse medidas para acercar el procedimiento de reclamo a las personas, como la difusión de información sobre su existencia, cómo y dónde debe reclamarse, etcétera (Mitchell, 2019). ${ }^{29}$

\section{Problemas de satisfacción y confianza en procedimientos de reclamo}

En la misma lógica, existe otro grupo de casos en los que la supervisión civil ha surgido para mejorar problemas de insatisfacción de la ciudadanía con el procedimiento de reclamo. Es decir, acá no existirían problemas de accesibilidad, sino que las dificultades se manifestarían por la manera en que el procedimiento está estructurado, lo que provoca que las personas sientan que no se les toma en serio, que no son tratadas imparcialmente o que no son escuchadas (Porter y Prenzel, 2015: 91). En esos casos, la principal preocupación de la supervisión será establecer y asegurar s de reclamo más justos e imparciales, con el fin de incrementar la satisfacción y la confianza por parte de los usuarios.

27. Para Chile, véase Beltrán (2018). Se trata de un estudio exploratorio que tuvo por objeto conocer y detectar barreras de acceso al procedimiento de reclamo por controles preventivos de identidad abusivos o denigratorios en algunas comisarías de la Región Metropolitana. El estudio sistematiza diversas razones que impedirían que este tipo de procedimientos, centralizados en comisarías, tengan éxito. Por ejemplo, la falta de conocimiento del derecho a reclamar, la falta de conocimiento de los funcionarios policiales sobre el procedimiento, la escasa información entregada por los funcionarios policiales sobre el funcionamiento del procedimiento de reclamo, funcionarios policiales en los accesos que actúan como una suerte filtro de acceso a la comisaría, etcétera.

28. Para más información, véase «What are the features of an effective police oversight body?», NACOLE, 2020, disponible en bit.ly/2TDuzxL.

29. Por ejemplo, la Oficina del Monitor Independiente de Denver tiene disponible un listado de lugares donde es posible encontrar formularios de reclamo con instrucciones para su llenado y presentación. 


\section{Problemas de confianza en las investigaciones internas}

Aunque existan s de reclamo accesibles y satisfactorios, pueden subsistir problemas en la etapa de investigación de la queja. Así, el hecho de que sea la policía quien investiga a sus propios funcionarios genera cierta desconfianza en la ciudadanía. Por tanto, aunque exista accesibilidad y satisfacción en el de reclamo, puede que en la etapa posterior (es decir, en la investigación) existan desconfianzas que, a los ojos de las personas, terminen transformando la investigación en algo meramente ilusorio. En estos casos, la supervisión civil se vuelve necesaria para promover investigaciones justas, minuciosas e independientes como condición esencial para construir e incrementar la confianza de la ciudadanía (Stone y Bobb, 2002: 3).

\section{Desmilitarización de las policías}

En otros casos, la supervisión civil surge de la necesidad de desmilitarizar la policía. En estos casos, la meta puede ser asegurar que la institución se reporte a la autoridad civil en lugar de la militar (United Nations Office on Drugs and Crime, 2011: 9), así como verificar que la respuesta que da la policía a la ciudadanía se realice a través de los medios acordes (President's Task Force on 21st Century Policing, 2015: 25)..$^{30}$ No se debe olvidar que la policía está lidiando con problemas de una comunidad determinada y no con combatientes armados en una zona de guerra. ${ }^{31}$ En este sentido, la supervisión civil ayudaría a controlar el tipo de respuesta que dan las policías a los problemas de la comunidad para la cual sirven. Por ejemplo, controlando el tipo de implementos y armamento que adquieren y utilizan, el tipo de entrenamiento que reciben, revisando protocolos de uso de fuerza, etcétera. ${ }^{32}$

30. Para más información, véase la recomendación 2.7.

31. Al respecto, en la ciudad de Ferguson, Missouri, una respuesta policial altamente militarizada se vivió a raíz de las protestas por la muerte a tiros del ciudadano afroamericano Michael Brown. La policía dispuso vehículos blindados y ametralladoras pesadas en contra de los manifestantes mientras disparaban balas de goma, gases lacrimógenos, bombas de humo y granadas aturdidoras. Para más información, véase Alana Horowitz, «Ferguson, Missouri Protest of Michael Brown Death Swarmed By SWAT Tea», HuffPost, 13 de agosto de 2014, disponible en bit.ly/2TDY $5 \mathrm{mV}$. En el caso de Chile, ha propósito del daño y riesgo asociado al uso de los perdigones de goma que dispara Carabineros en contra de manifestantes, Velásquez y Fernández concluyen que «no es admisible que en una democracia no exista o se ejerza un control civil técnico que sea capaz de analizar los riesgos del uso del armamento policial, y menos aún que los protocolos del uso de este armamento sean determinados autónomamente por la policía, sin estar sujetos a control civil alguno». Para más información, véase Javier Velásquez y Catalina Fernández, «¿No letales? El daño que ha causado la munición que dispara Carabineros a los manifestantes y por qué debe prohibirse», Ciper Chile, 27 de mayo de 2020, disponible en bit.ly/34D5Aky. Para una perspectiva más amplia del problema de la policía militarizada con una perspectiva tanto nacional como comparada, véase Pascual Cortés, «El problema de una policía militarizada», Ciper Chile, 12 de junio de 2020, disponible en bit.ly/2JjUeK1.

32. En Estados Unidos, durante el gobierno de Barack Obama, se establecieron limitaciones para que las policías adquirieran armamento militar. Sin embargo, dicha prohibición fue levantada por Donald Trump 


\section{Supervisión civil como desincentivo a la mala conducta policial}

Sin importar el modelo de supervisión que se adopte, cada vez que se crea un organismo de esta naturaleza se producirá naturalmente un efecto de desincentivo a la mala conducta policial, alentando así el buen comportamiento (De Angelis y otros, 2016: 3). De hecho, se ha establecido que estos controles civiles son más efectivos que otro tipo de controles externos, como los juzgados civiles o criminales y los controles a través de órganos legislativos (Clarke, 2009: 2).

Es importante destacar que una de las principales funciones del oversight es la de hacer recomendaciones a nivel individual e institucional, lo que podría alentar la buena conducta policial. En una esfera individual, podría ocurrir que una agencia de supervisión civil recomiende a un funcionario policial ser reentrenado en un área determinada. Así, este podría ser capaz de aprender mucho mejor cómo desarrollar su trabajo (Finn, 2001: 12). Por otro lado, en una dimensión institucional, a través de la revisión de protocolos y s, la supervisión civil puede ayudar a la policía a desarrollar exitosamente sus funciones, incrementando el entendimiento por parte de estos de las reales necesidades de los ciudadanos a quienes sirven (Miller, 2002: 3; Finn, 2001: 12).

\section{Supervisión civil como manifestación democrática}

Establecer un mecanismo de control civil también tiene un significado democrático. Estos organismos no solo representan la idea de que los ciudadanos debieran poder influir en su gobernanza lo más posible (Miller, 2002: 3), sino que también generan un ambiente que fomenta la rendición de cuentas, la cercanía y la transparencia hacia las comunidades que sirven, ya que no se debe olvidar que las policías, en tanto agentes del Estado, entregan un servicio a los ciudadanos. Así, la supervisión civil es útil para mejorar el servicio y la respuesta de las policías, ya que las personas tienen una suerte de conocimiento especial y están en una posición privilegiada para explicar a la policía cuáles son sus necesidades realmente (Miller, 2002: 3; Finn, 2001: 12). Además, en este contexto, establecer una agencia de supervisión civil como canal de comunicación necesariamente mejorará la relación entre la comunidad y la policía, creando instancias de diálogo en las que las policías reciben feedback sobre su trabajo y, al mismo tiempo, las personas presentan a estas sus inquietudes.

La supervisión civil también fomenta una activa participación ciudadana, ya que, para cumplir realmente con su función, requiere del compromiso de la ciudadanía para llevar adelante las funciones de revisión, investigación, decisión, monitoreo, etcétera (Hryniewicz, 2011: 79). Del mismo modo, en los casos en que estas agencias de oversight se encargan de arribar a decisiones en casos de mala conducta policial, al actuar como una suerte de tribunal se está asegurando que dicha decisión sea

en septiembre de 2017. Tras la muerte de George Floyd, el debate sobre la desmilitarización de la policía ha surgido nuevamente. 
tomada de forma democrática, legitimándola a través del uso de estas instituciones (Hryniewicz, 2011: 81).

\section{Aproximación a algunos modelos de civilian oversight}

Es prácticamente imposible encontrar dos modelos idénticos de supervisión civil en Estados Unidos y la razón es bastante sencilla. Cada una de estas agencias han sido creadas como respuesta a las necesidades específicas de una jurisdicción particular, estableciendo diferentes estructuras, poderes y metas. En otras palabras, cuando dichas agencias fueron creadas, existía una tensión política, social o cultural que determinó tanto la creación del mecanismo como su estructura, lo que explicaría la gran variedad de modelos existentes (De Angelis y otros, 2016: 6). Así las cosas, no existen modelos «de talla única», sino que estos se crean y configuran caso a caso (OIR Group, 2017: 3)

A partir de lo anterior, ha sido difícil crear categorías rígidas de los modelos de supervisión disponibles, sin embargo, han existido esfuerzos por desarrollar clasificaciones que permitan explicar sus naturalezas. El primero en hacerlo fue Samuel Walker (2001: 138), quien presentó esta sofisticada clasificación:

- Modelos de clase I: Corresponden a las agencias que son independientes del departamento de policía que supervigilan y que, además, conducen investigaciones completamente independientes por casos de mala conducta policial.

- Modelos de clase II: Son los sistemas que pueden revisar y comentar sobre investigaciones internas conducidas por la propia policía.

- Modelos de clase III: Funcionan como una suerte de tribunal de apelaciones.

- Modelos de clase IV: Se conforman como entidades con capacidad de auditar, monitorear y revisar el sistema de manejo de quejas en contra de la policía.

- Modelos de clase V (o agencias híbridas): Incluye a todos los organismos que involucran a personas que no forman parte de la policía, quienes tienen una suerte de aporte o contribución con la institución o alguna clase de control sobre los s de queja o reclamo.

En la actualidad, con el paso de los años y el surgimiento de nuevos modelos, varios autores han actualizado esta clasificación. Así, para efectos de este trabajo, se seguirá la propuesta en De Angelis y otros (2016: 7). A continuación, se analizarán brevemente cuatro modelos de supervisión y se describirá, a través de algunos ejemplos concretos, la manera en que operan dichos mecanismos y sus principales características.

\section{Modelo centrado en investigación}

Se considera como la forma más independiente de supervisión (De Angelis y otros, 2016a: 8). Usualmente, las policías, a través de asuntos internos, realizan el trabajo de investigación de su propio departamento. En otras palabras, «la policía se investiga a sí 
misma», cuestión que levanta de inmediato cuestiones de legitimidad, sesgos e imparcialidad. En cambio, a través de este tipo de mecanismos, se entrega a un órgano externo el poder de conducir, de manera independiente, investigaciones sobre quejas y reclamos por mala conducta de oficiales de la policía. Esto puede ocurrir porque se le quita por completo el poder de investigación al departamento de asuntos internos o porque se realizan investigaciones paralelas, manteniendo asuntos internos la facultad de investigar (De Angelis y otros, 2016a: 7; Police Assessment Resource Center, 2005: 14).

La capacidad de investigar de manera independiente ayuda a dar una imagen de que las investigaciones son más completas, minuciosas y menos sesgadas al ser desarrolladas por personal ajeno a la institución policial. ${ }^{33}$ De esta manera, se contribuye a incrementar la confianza de las personas en la integridad del proceso de investigación (De Angelis y otros, 2016a: 7; Police Assessment Resource Center, 2005: 14-16). Además de esto, como se verá en los siguientes apartados, este tipo de mecanismos puede tener algunas funciones adicionales.

\section{Departamento de Responsabilidad Policial de San Francisco}

En 1983, la ciudad de San Francisco, perteneciente al Estado de California, estableció la Oficina de Quejas Ciudadanas, posteriormente renombrada Departamento de Responsabilidad Policial o Department of Police Accountability (DPA). ${ }^{34}$ Se trata de una entidad independiente compuesta de ciudadanos que nunca han trabajado para la policía con la misión de investigar de manera rápida, justa e imparcial las quejas contra los agentes de policía de San Francisco. Asimismo, el DPA no solo puede hacer recomendaciones sobre las políticas y protocolos de la institución, sino también auditar periódicamente a la policía. ${ }^{35}$

El DPA también sirve como un espacio físico donde los ciudadanos pueden presentar sus quejas en contra de los oficiales de la policía. Estos reclamos pueden ser presentados a través de internet, por teléfono, vía correo electrónico o personalmente. ${ }^{36}$ Asimismo, se permite ingresar quejas anónimas, las cuales deben sostenerse con evidencia adicional.

Una vez que se lleva a cabo la investigación y se establece que hubo mala conducta policial, el DPA envía un reporte sobre lo indagado con recomendaciones de sanciones,

33. Sin embargo, han existido agencias compuestas por exfuncionarios de la policía, quienes están a cargo de las investigaciones. Con todo, la tendencia actual es que, para formar parte de la agencia de supervisión, es requisito no haber trabajado antes para el departamento de policía que se supervigila.

34. Para más información, véase «Home», San Francisco Department of Police Accountability, 2019, disponible en bit.ly/35NkizP.

35. Para más información, véase «Statistical Summary», San Francisco Department of Police Accountability, 2019, disponible en bit.ly/38080dt.

36. Para más información, véase «¿Tiene una queja sobre algún miembro del departamento de policía de San Francisco o sobre el accionar policial?», San Francisco Department of Police Accountability, 2020, disponible en bit.ly/37WS9oE. 
las que van desde amonestaciones escritas y suspensiones hasta despidos. Si la sanción recomendada es menor a 10 días de suspensión, quien decidirá será el jefe de policía. En cambio, si la sanción excede ese rango de días, el caso se deriva a la Comisión de Policía de San Francisco para que decida. ${ }^{37}$ Cuando las sanciones son impuestas directamente por el jefe de la policía, la Comisión actúa como un tribunal de apelación. ${ }^{38}$

Finalmente, el DPA produce un reporte en el que da cuenta del manejo de casos, es decir, indica cuántos se han iniciado o cerrado y cuántas investigaciones han sido completadas. Asimismo, el reporte contiene un análisis de las sanciones que se han propuesto y de las que el jefe de policía ha adoptado. Finalmente, se incluye un análisis de la cantidad de reclamos presentados por distritos. ${ }^{39}$

\section{Junta de Revisión Ciudadana de Atlanta}

Durante 2007, en Atlanta, perteneciente al Estado de Georgia, se estableció el denominado Atlanta Citizen Review Board (ACRB) (Code of Ordinances of Atlanta City, 2020: Part II [General Ordinances], Article XVI [Boards, Councils, Commissions and Authorities], Division 11 [Citizen Review Board], $\$$ 2-2201 [Establishment of the Atlanta Citizen Review Board] $)^{40}$ como respuesta de parte de las autoridades de la ciudad a problemas de legitimidad de la policía derivados de un incidente ocurrido en 2006, en que una anciana murió durante la ejecución de una orden de allanamiento (Stephens y otros, 2018: 14).

La Junta se compone de once miembros, quienes entre sus calificaciones deben tener experiencia como oficial de policía, investigador criminal o agente especial, entre otros. En su defecto, deben contar con experiencia en derechos civiles, litigación o liderazgo, entre otros (Code of Ordinances of Atlanta City, 2020: Part II, Article XVI, Division 11, $\$ 2-2203$ [Appointment of Members]). ${ }^{41}$

El objetivo de ACRB es entregar a la comunidad una instancia abierta y justa para recibir, investigar y hacer responsables a los oficiales de policía. De este modo, al supervigilar las acusaciones de mala conducta en contra de miembros policiales, se promue-

37. La Comisión de Policía de San Francisco es el organismo que establece las políticas del departamento de policía, lleva a cabo audiencias disciplinarias por casos de mala conducta e impone sanciones en dichos casos. Además, funciona como tribunal de apelación cuando las sanciones son impuestas por el jefe de la policía.

38. Para más información, véase «Police Commission», San Francisco Department of Police Accountability, 2020, disponible en bit.ly/2TAQpSC.

39. Para más información, véase «Statistical Summary», San Francisco Department of Police Accountability, 2019, disponible en bit.ly/38080dt.

40. Para más información, véase «Sec. 2-2202. - Definitions», City of Atlanta, 22 de diciembre de 2020, disponible en bit.ly/3nYxezr.

41. Para más información, véase «Sec. 2-2203. - Appointment of members», City of Atlanta, 22 de diciembre de 2020 , disponible en bit.ly/38QnSzM. 
ve la confianza de la ciudadanía en la institución..$^{42}$ Entonces, su función principal es la recepción e investigación de reclamos en contra de los funcionarios. Posteriormente, la Junta revisa el reclamo e instruye una investigación independiente con posibilidades de mediación.

Una vez que se inicia el proceso investigativo con la presentación del reclamo, este se evalúa y comienza la etapa de recolección de información y evidencia. Además, se obtiene una declaración del reclamante, del oficial involucrado y de los testigos. Después de esto, se presenta un resumen de la investigación al director de la Junta, quien somete la investigación a revisión de la Junta en Pleno para adoptar una decisión o una recomendación. Finalmente, la determinación es comunicada al jefe de la policía, quien tiene la última palabra. ${ }^{43}$

En cuanto a la accesibilidad, un elemento destacable de la Junta es que periódicamente se realizan audiencias públicas para conocer las inquietudes de la comunidad en torno a cuestiones policiales, así como campañas educativas (Atlanta Citizen Review Board, 2019: 5). Por otro lado, la Junta puede aconsejar o efectuar recomendaciones al alcalde, al Consejo Municipal y al jefe de la policía con la finalidad de mejorar la capacidad de la policía para llevar cabo sus funciones y para mejorar la relación con la comunidad (Code of Ordinances of Atlanta City, 2020: Part II, Article XVI, Division 11, $\$ 2-2211$ [Compensation; conflict of interest; removal]). ${ }^{44}$

La Junta también ofrece un interesante programa de mediaciones con el objetivo de aumentar la satisfacción del reclamante con el resultado de su caso. Así, cuando se presenta un reclamo, este se evalúa y se ofrece participar del proceso a los involucrados. ${ }^{45} \mathrm{Si}$ estos acceden, se agenda y se lleva adelante. Si se llega a algún acuerdo, se cierra el caso y no se lleva adelante ninguna actividad investigativa. Ahora bien, los únicos casos elegibles para mediación son los que involucran abuso de autoridad, como una detención menor, y los casos de descortesía y lenguaje, siempre que no se encuentren relacionados con raza, género y/u orientación sexual. ${ }^{46}$

Finalmente, la Junta produce un informe anual que da cuenta, entre otras cosas, de las principales actividades llevadas a cabo por el organismo. Además, se encarga de presentar cifras relevantes en cuanto a cantidad de reclamos recibidos e investigados,

42. Para más información, véase «Home», Atlanta Citizen Review Board, 2020, disponible en bit. ly/3jQSFjr.

43. Para más información, véase «Investigative Process», Atlanta Citizen Review Board, 2020, disponible en bit.ly/3mDBDXO.

44. Para más información, véase «Sec. 2-2211. - Compensation; conflict of interest; removal», City of Atlanta, 22 de diciembre de 2020, disponible en bit.ly/3huSvP8.

45. Existen materiales informativos diferenciados para ciudadanos y policías. Para más información, véase «Citizen Mediation», Atlanta Citizen Review Board, 2020, disponible en bit.ly/35MwOV3 y «Police Mediation», Atlanta Citizen Review Board, 2020, disponible en bit.ly/31XkIHE.

46. Para más información, véase «FAQ Mediation», Atlanta Citizen Review Board, 2020, disponible en bit.ly/zedgcwK. 
investigaciones completadas, tiempos en que estas se desarrollan, resoluciones y sanciones impuestas en investigaciones cerradas, etcétera (Atlanta Citizen Review Board, 2019).

\section{Modelo centrado en revisión}

A diferencia de los modelos basados en la investigación, el modelo de revisión busca examinar la calidad de las investigaciones llevadas a cabo por el departamento de asuntos internos de la policía (De Angelis y otros, 2016: 10). En general, estos mecanismos comienzan su trabajo una vez que la policía ha finalizado la investigación de un reclamo (Police Assessment Resource Center, 2005: 11). Entonces, lo usual es que el departamento de asuntos internos aún mantenga el poder de investigar, pero que, una vez finalizadas dichas indagaciones, se envíen a una suerte de evaluación externa a cargo de este tipo de juntas o comités.

En general, estos mecanismos carecen de herramientas que permitan, bajo apercibimientos legales, requerir la producción de documentos, la obtención de testimonios o ciertas facultades de investigación. ${ }^{47} \mathrm{Su}$ función principal está orientada al estudio de investigaciones finalizadas y luego, en base a su revisión, efectuar recomendaciones al jefe del departamento de policía sobre si los resultados de esta debiesen mantenerse o ser revertidos. De todas formas, puede que se requiera efectuar una labor adicional o una investigación completamente nueva (Police Assessment Resource Center, 2005: 11). Ahora, entre las diversas variaciones que es posible encontrar, además de evaluar investigaciones finalizadas y efectuar recomendaciones al respecto, también existen modelos centrados en revisión que pueden recibir reclamos directamente de la comunidad, escuchar apelaciones y resolverlas, llevar adelante audiencias públicas, hacer recomendaciones al departamento de policía para futuras investigaciones o llevar a cabo actividades de difusión comunitaria (De Angelis y otros, 2016: 10).

En términos económicos, es el mecanismo menos costoso (De Angelis y otros, 2016a: 14), por lo que generalmente no se cuenta con un staff a tiempo completo (Police Assessment Resource Center, 2005: 12). Incluso, es posible encontrar casos en que estos mecanismos funcionan en base a un servicio voluntario comprometido por los ciudadanos.

47. Aunque es posible encontrar algún caso, dichos poderes son más bien limitados. En el caso que se presenta, la Junta de Revisión de la Policía de Urbana originalmente tenía mayores poderes de investigación y disciplinarios en su propuesta inicial, sin embargo, la ordenanza que se aprobó eliminó dichas funciones. Tanto así que algunos residentes consideran dicha junta como un «timbre de goma» más dentro de los procesos internos de la policía. Véase Christopher Hansen, «Urbana Civilian Police Review Board Under the Spotlight After Violent Arrest», The Public, mayo de 2020, disponible en bit.ly/2TBoaDd. 


\section{Junta de Revisión de la Policía de Urbana}

La Junta de Revisión de la Policía o Civilian Police Review Board (CPRB) fue creada en 2011 en la ciudad de Urbana, perteneciente al Estado de Illinois, con el objetivo de mejorar las interacciones de la comunidad con la policía, supervigilar investigaciones internas y establecer un proceso justo e independiente en la revisión de reclamos, entre otros (Urbana City Code, 2020: Chapter 19 [Police], Article III [Civilian Police Review Board], Division 1 [Generally] \$ 19-20 [Establishment and purpose]) $)^{48}$ (City of Urbana Civilian Police Review Board, 2012: 3). ${ }^{49}$

Esta Junta se compone de siete miembros que son nombrados por el alcalde de la ciudad con aprobación del Consejo Municipal. La composición del Comité debe reflejar toda la diversidad de la comunidad, incluyendo a personas provenientes de diferentes barrios, niveles de ingreso, etnias, edades, géneros y experiencias (Urbana City Code, 2020: Chapter 19, Article III, Division 1, $\$ 19-21$ [Composition]) $)^{50}$ (City of Urbana Civilian Police Review Board, 2012: 4). Asimismo, debe tratarse de personas con una reputación caracterizada por los principios de justicia, integridad y vocación de servicio público, y no deben haber sido empleados de ninguna agencia policial ni deben registrar antecedentes penales (Urbana City Code, 2020: Chapter 19, Article III, Division 1, $\$ 1$ 19-22 [Qualification for membership]). ${ }^{51}$ Estos miembros no reciben remuneración o compensación por el desempeño de su trabajo.

El de reclamo por mala conducta policial comienza con la presentación de la queja en una oficina dispuesta especialmente para ello, distinta al CPRB. Allí, las personas llenan un formulario especial que tiene el valor de una declaración jurada con todas las consecuencias jurídicas que esto implica. Es importante mencionar que existen límites temporales en la presentación de un reclamo, ya que deben ser presentados dentro de un plazo de 45 días hábiles administrativos o, en caso de impedimento físico del reclamante, dentro de 15 días hábiles desde que cese el impedimento. En cualquier caso, no se podrán presentar reclamos luego de un año de ocurrido el incidente (Urbana City

48. Para más información, véase «Sec. 19-20. - Establishment and purpose», Urbana, IL, 8 de julio de 2020, disponible en bit.ly/34Reomk.

49. Con todo, esta Junta ha sido criticada porque se han tardado en evacuar los informes requeridos por la legislación local en un periodo considerable de tiempo. Del mismo modo, se han criticado sus reales poderes para producir un real efecto de desincentivo a la mala conducta policial -particularmente corrupción- dentro del departamento de la policía. Las críticas han apuntado a que, por tratarse de una Junta en base a voluntariado, no existen realmente recursos para hacer una revisión y supervisión efectiva de la policía.

50. Para más información, véase «Sec. 19-21. - Composition», Urbana, IL, 8 de julio de 2020, disponible en bit.ly/3rGuzzo.

51. Para más información, véase «Sec. 19-22. - Qualifications for membership», Urbana, IL, 8 de julio de 2020, disponible en bit.ly/2LiRnGz. Sobre este aspecto, es interesante la diferencia de la regulación de Urbana en relación con la regulación de Madison, donde se espera que quienes formen parte de dicho Comité sean personas con antecedentes penales o, al menos, con cierto involucramiento con la policía, personas sin hogar, entre otras. 
Code, 2020: Chapter 19, Article III, Division 2 [Complaint procedures, investigation

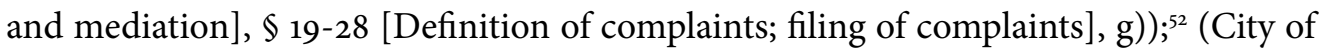
Urbana Civilian Police Review Board, 2012: 6-10).

Una vez presentado el reclamo, se envía una copia al departamento de policía y se notifica también al CPRB (Urbana City Code, 2020: Chapter 19, article III, division 2, $\$ 19-28$, i) y j)).53 Ante esto, el primero debe iniciar y desarrollar una investigación para luego notificar sus resultados tanto al CPRB como al reclamante (Urbana City Code, 2020: Chapter 19, article III, division 2, $\$ 19-28, \mathrm{k})$ ). ${ }^{54}$ Notificados los resultados, en caso de que no resulten satisfactorios para el reclamante, este tiene derecho a deducir recurso de apelación, el cual será conocido y resuelto por el CPRB (Urbana City Code, 2020: Chapter 19, Article III, Division 2, $\$ 19-28, \mathrm{~m})$ y $\$ 19-32$ [Appeal of police department findings to the CPRB]; Division 3 [Administration and enforcement], $\$ 19-34$ [Report to the chief of police], b)).55

Entre sus funciones como mecanismo alternativo a la solución de conflictos, el $\mathrm{CPRB}$ ofrece un servicio de mediación gratuito y confidencial que es llevado a cabo ante expertos. Así, cada vez que se recibe un reclamo, la Junta notifica al reclamante de la opción de terminar su reclamo a través de una mediación (Urbana City Code, 2020: Chapter 19, article III, division 2, $\$ 19-29),{ }^{56}$ cuyas sesiones se llevarán a cabo en los lugares, fechas y horarios que las partes determinen (Urbana City Code, 2020: Chapter 19, article III, division 2, $\$ 19-30) .57$

Por último, para asegurar la accesibilidad, en el sitio web de la ciudad se encuentra disponible tanto la información de contacto de todos los miembros de la Junta como de las reuniones en general, sus fechas y horarios, tablas respectivas, minutas de las ya realizadas y la documentación relevante. Por si fuera poco, estas se transmiten vía streaming, lo que permite que puedan ser consultadas posteriormente, ya que todas se encuentran disponibles en el mismo sitio. ${ }^{58}$ Además, al inicio de cada reunión de

52. Para más información, véase «Sec. 19-28. - Definition of complaints; filing of complaints», Urbana, IL, 8 de julio de 2020, disponible en bit.ly/2L3Xkma.

53. Para más información, véase «Sec. 19-28. - Definition of complaints; filing of complaints», Urbana, IL, 8 de julio de 2020, disponible en bit.ly/2L3Xkma.

54. Para más información, véase nota anterior.

55. Para más información, véase nota 53. Luego, véase «Sec. 19-32. - Appeal of police department findings to the CPRB, Urbana, IL, 8 de julio de 2020, disponible en bit.ly/34PDnqg. En su literal i) establece una importante prohibición, en el sentido de que los resultados y conclusiones a que arribe el CPRB luego de conocer la apelación, no podrán ser utilizados como evidencia en otra causa criminal o civil. Asimismo, es relevante mencionar que el CPRB no tiene autoridad disciplinaria sobre la policía, por lo que su procedimiento es relevante únicamente en cuanto a la determinación de hechos, hallazgos y conclusiones.

56. Para más información, véase «Sec. 19-29. - Mediation notice», Urbana, IL, 8 de julio de 2020, disponible en bit.ly/37Xw9Cz.

57. Para más información, véase «Sec. 19-30. - Mediation process», Urbana, IL, 8 de julio de 2020, disponible en bit.ly/37ZHqT3.

58. Para más información, véase «Civilizan Police Review Board (CPRB), City of Urbana, 2020, disponible en bit.ly/3kLo73D. 
la Junta se abre un espacio de participación pública, en el que se reciben opiniones, críticas y, en general, cualquier preocupación de parte de la ciudadanía. Esta suerte de micrófono abierto o espacio para oír a la ciudadanía es de uso común por los residentes de la ciudad.

\section{Modelos centrados en seguimiento, auditoría o monitoreo}

Es la forma más reciente de supervisión policial. El foco de estos modelos es la revisión de problemas de orden sistémico al interior un departamento de policía (Police Assessment Resource Center, 2005: 21). Así, el núcleo esencial del trabajo de un monitor independiente o auditor es promover reformas sistemáticas a gran escala de las organizaciones policiales, mientras que, al mismo tiempo, se revisan incidentes críticos en particular o denuncias individuales (De Angelis y otros, 2016: 11; King, 2015: 101). Relevante es que el monitor o auditor independiente no le quita el poder de investigación al departamento de policía. Por el contrario, al mantener en la sección de asuntos internos la facultad de investigar se estaría incentivando una cultura de responsabilización interna en la policía (Police Assessment Resource Center, 2005: 21).

En términos generales, el auditor o monitor es un profesional contratado a tiempo completo y cuenta amplios conocimientos en temas policiales, quien, además, puede tener otras funciones adicionales, como recibir quejas o reclamos por parte de la comunidad, monitorear investigaciones en curso, conducir personalmente o nombrar a un investigador independiente en los casos más serios, hacer recomendaciones sobre la aplicación de medidas disciplinarias, cumplir ciertos deberes de publicidad y, en general, hacer recomendaciones para mejorar protocolos policiales, prácticas y entrenamiento, entre otros.

\section{Monitor independiente de New Orleans}

En 2009, la ciudad de New Orleans, perteneciente al Estado de Luisiana, instauró la Oficina del Monitor Independiente de la Policía (OIPM) con el objetivo de mejorar el servicio y promover tanto la eficiencia como la efectividad del departamento de policía de la ciudad con el fin de aumentar la confianza pública (Independent Police Monitor, 2020; Police Assessment Resource Center, 2016: 8). ${ }^{59}$ En general, desde la década del ochenta hasta mediados de la década del noventa, la policía de New Orleans ocupaba los titulares de la prensa de Estados Unidos por diversos escándalos asociados a la comisión de delitos, asesinatos, violaciones y robos. De ahí en más, una serie de reformas

59. Aunque en sus orígenes la Oficina del Monitor Independiente formaba parte y estaba sujeta al presupuesto de la Oficina del Inspector General, en 2015 el organismo se desprendió y, en la actualidad, cuenta con un presupuesto y una autonomía mucho mayores. Para complementar, véase «The New Orleans Independent Police Monitor, Independent Police Monitor», 2020, disponible en bit.ly/35SG1Vo. 
fue sacada adelante hasta, finalmente, avanzar a la adopción e implementación de un monitor independiente. ${ }^{60}$

El modelo adoptado en New Orleans es complejo, ya que el monitor tiene una gran cantidad de responsabilidades, todas muy variadas. En general, le corresponde enfocarse en reclamos por mala conducta, pero también debe efectuar revisiones integrales al departamento de policía, sus operaciones, datos, manejo de riesgos, políticas, recursos, etcétera (New Orleans City Code, 2020: Chapter 2 [Administration], Article XIV [Office of the Independent Police Monitor], \$ 2-1121 [Office of Independent Police Monitor], 3) y 16)). ${ }^{61} \mathrm{~A}$ continuación, se dará cuenta de los aspectos principales de este mecanismo.

El monitor es nombrado por períodos de cuatro años y puede servir en su cargo hasta por dos períodos consecutivos con aprobación del Consejo Ético de la ciudad (New Orleans City Code, 2020: Chapter 2, article XIV, \$ 2-1121, 1), b)).$^{62}$ En cuanto a sus calificaciones, debe ser un abogado con experiencia relevante en derecho penal, derechos civiles o investigaciones corporativas o gubernamentales. También puede ser un individuo con al menos cinco años de experiencia en supervisión de agencias de cumplimiento de la ley que haya obtenido una licenciatura de educación superior (New Orleans City Code, 2020: Chapter 2, article XIV, \$ 2-1121, 1) y 2)). ${ }^{63}$

En particular, la OIPM tiene el deber de monitorear los reclamos tanto de civiles externos como internos, las investigaciones internas, la imposición de sanciones disciplinarias, y los incidentes de uso de fuerza y muertes ocurridas bajo custodia policial. Asimismo, tiene el deber de revisar y analizar el número y tipo de reclamos recibidos, evaluar los plazos de las investigaciones internas, revisar la efectividad y las operaciones del sistema de alerta temprana, la integridad del departamento, sus recursos y, en general, cualquier aspecto relacionado con la supervisión, entrenamiento y sanciones disciplinarias. Luego, debe llevar a cabo análisis de riesgos y establecer patrones relevantes a nivel de departamento. Para esto, no solo debe analizar los reclamos de parte de la ciudadanía, sino también demandas civiles por incidentes con la policía, pagos efectuados por concepto de indemnizaciones, etcétera. Por último, debe desarrollar cualquier otra tarea que asegure la responsabilización, la transparencia y la respuesta a la ciudadanía por parte del departamento de policía de New Orleans (New Orleans City Code, 2020: Chapter 2, article XIV, $\$ 2-1121,3){ }^{64}$

En cuanto al procedimiento de reclamo, la oficina del monitor es un lugar habilitado para recibir reclamos por casos de mala conducta, los cuales son posteriormente

60. Para más información, véase «History», Independent Police Monitor, 2020, disponible en bit. ly/30HiO>P.

61. Para más información, véase «Sec. 2-1121. - Office of independent police monitor», New Orleans City Council, 30 de noviembre de 2020, disponible en bit.ly/2WRyDw3.

62. Para más información, véase nota 61 .

63. Para más información, véase nota 61 .

64. Para más información, véase nota 61. 
enviados al departamento de investigaciones internas de la policía para iniciar el procedimiento (New Orleans City Code, 2020: Chapter 2, article XIV, $\$ 2-1121,4)$ ). ${ }^{65}$ Es importante mencionar que el monitor efectúa una revisión de la clasificación de dicho reclamo de acuerdo con la naturaleza del incidente y, en su caso, puede recomendar la reclasificación (New Orleans City Code, 2020: Chapter 2, article XIV, $\$ 2-1121,5)$ ). ${ }^{66}$ Asimismo, puede recomendar la reapertura de investigaciones cerradas cuando determine que aquellas no fueron llevadas a cabo de manera justa y minuciosa, siempre y cuando no hayan transcurrido los plazos de prescripción. La decisión de reapertura, sin embargo, es de resorte de la policía (New Orleans City Code, 2020: Chapter 2, article XIV, \$ 2-1121, 6) y 8)). ${ }^{67}$

Desde 2014, la OIPM ofrece un servicio de mediación a la ciudadanía como una vía alternativa a la investigación de reclamos. Es un procedimiento alternativo que tiene como objeto reconstruir la confianza en la policía, mejorar las relaciones entre la policía y la comunidad e incrementar el entendimiento que tienen las policías de las necesidades de la comunidad a la cual sirven. Es un procedimiento confidencial que entrega un espacio seguro y neutral, en el que las partes involucradas pueden interactuar de manera auténtica y segura sobre el conflicto para arribar a una solución. ${ }^{68}$

El monitor también debe revisar y analizar patrones o tendencias para evaluar y determinar ciertos riesgos o problemas sistémicos en el departamento policial. Así, no solo debe analizar los reclamos por parte de la ciudadanía, sino también identificar patrones en demandas civiles por mala conducta policial, analizando las indemnizaciones pagadas, las unidades policiales o los funcionarios que han sido objeto de reclamos frecuentemente, etcétera. En estos casos, deberá revisar la investigación subyacente que se llevó a cabo en los casos de las demandas civiles, así como los reclamos internos por los mismos hechos. ${ }^{69}$ Del mismo modo, el monitor debe visitar y revisar periódicamente sesiones de entrenamiento de la policía para identificar buenas prácticas y aspectos que se necesiten mejorar, tanto en lo relativo al programa de entrenamiento como a su frecuencia. ${ }^{70}$

Finalmente, también existen ciertos deberes de acercamiento con la comunidad para asegurar procedimientos accesibles. De esta manera, el monitor debe llevar a cabo reuniones públicas con diferentes segmentos de la comunidad cada cuatro meses, distribuir información sobre su oficina, sus deberes, sus funciones, entre otras. Además,

65. Para más información, véase nota 61.

66. Para más información, véase nota 61.

67. Para más información, véase nota 61. Esto también puede ocurrir a instancia del reclamante cuando, notificado del resultado de la investigación, no se encuentra satisfecha con este. Asimismo, durante el desarrollo de la investigación, los reclamantes pueden solicitar al monitor la entrega de un reporte del estado actual de la investigación.

68. Para más información, véase «Home», New Orleans Community-Police Mediation Program, 2020, disponible en bit.ly/3jEfNBj.

69. Para más información, véase New Orleans City Code $\$ 2-1121(9)$.

70. Para más información, véase New Orleans City Code $\$ 2$ 2-1121(11). 
debe asegurarse de que los formularios de reclamo sean redactados en un lenguaje y formato accesible a la ciudadanía. ${ }^{71}$

\section{Modelos híbridos}

En la actualidad, la tendencia es la creación de mecanismos que se podrían caracterizar como híbridos, ya que incorporan una combinación de funciones de los mecanismos previamente descritos (Attard y Olson, 2013: 2). De este modo, se incorporan aspectos de mecanismos centrados en investigación y revisión, con aspectos de modelos basados en auditorías o monitoreos independientes. Al mismo tiempo, puede que en la composición del órgano exista una combinación de civiles y personal policial (Mugari, 2018: 6). En fin, las posibilidades son infinitas.

A continuación, se describirá el modelo híbrido de supervisión civil que se está implementando actualmente en la ciudad de Madison, el cual está integrado por un monitor independiente y un Comité de Supervisión Civil.

\section{Oficina del Monitor Independiente y Comité de Supervisión Civil de Madison}

La ciudad de Madison, perteneciente al Estado de Wisconsin, no ha sido la excepción a la tendencia de instaurar mecanismos de supervisión civil. Así, luego de una serie de escándalos de mala conducta policial, ${ }^{72}$ en 2015 las autoridades crearon un Comité compuesto de civiles representativos de toda la comunidad de Madison con la misión de desarrollar una revisión integral del departamento de policía, lo que incluía su cultura, entrenamiento, políticas, protocolos y procedimientos (Findley y otros, 2019: 171-172). En octubre de 2019, y luego de cuatro años de trabajo, el Comité hizo público su reporte final con la recomendación central de instaurar un mecanismo de civilian oversight, el cual actualmente está en proceso de implementación. La propuesta del Comité consiste en establecer un mecanismo bicéfalo de carácter híbrido, compuesto por una Oficina del Monitor Independiente (IMO) y por un Comité de Supervisión Civil (COB).

El puesto de monitor independiente debe ser ocupado por una persona que nunca haya trabajado para el Madison Police Department (MPD), con suficiente formación en derechos civiles y equidad, y con conocimiento sobre supervisión civil y buenas prácticas policiales (Findley y otros, 2019: 32). Entre sus facultades destaca el derecho a cooperación plena por parte del MPD, lo que incluye acceso a todos los registros, ar-

\footnotetext{
71. Para más información, véase New Orleans City Code $\$$ 2-1121(12).

72. Si bien la decisión de las autoridades de la ciudad se debió a una serie de incidentes de mala conducta policial, el hito ocurrió el 6 de marzo de 2015 cuando Tony Robinson recibió un disparo y murió a manos de la policía. Esto no solo desató protestas, sino que también elevó las tensiones entre la policía y la comunidad afroamericana de la ciudad, por lo que el tema del uso excesivo de la fuerza se puso sobre la mesa, especialmente cuando se hizo pública la información de que el oficial que dio muerte a Robinson había estado involucrado en otro tiroteo con resultados fatales unos años atrás. Para más información, véase «Tony Robinson Shooting Wisconsin Dashcam Footage Released», The Guardian, disponible en bit.ly/34De76S.
} 
chivos, protocolos, datos y cualquier información que sea necesaria para llevar adelante sus funciones. Asimismo, ostenta el poder de requerir, bajo apercibimientos legales, declaraciones de testigos y la producción de documentos. Como contrapeso, se establecen fuertes deberes de confidencialidad (Findley y otros, 2019: 32).73

La principal función de la IMO es monitorear de forma activa el cumplimiento por parte de la policía de toda la normativa interna del departamento, procedimientos, leyes, órdenes de las autoridades de la ciudad y recomendaciones emanadas del propio Comité. Asimismo, debe monitorear todas las investigaciones que involucren una posible mala conducta. ${ }^{74}$ Otra función central del monitor independiente es realizar recomendaciones en diferentes áreas. Por ejemplo, recomendaciones sobre la imposición de medidas disciplinarias, sobre derivar casos al Comité de Policía y Bomberos para la imposición de una sanción disciplinaria sobre la función policial (Wisconsin State Legislature, 2017-18: $\$ 62.13$ [Police and fire departments]) ${ }^{75} \mathrm{y}$, en general, abordar cualquier otra inquietud de la comunidad, de los miembros del $\mathrm{COB}$, del jefe de la policía, del personal del MPD y de las autoridades de la ciudad (Findley y otros, 2019: 32).

Para asegurar accesibilidad, la IMO debe establecer un proceso para recibir e investigar quejas y reclamos de la ciudadanía en contra de miembros del MPD. Asimismo, el monitor puede nombrar a un abogado para que represente a la persona agraviada que litigue su caso ante la Comisión de Policía y Bomberos (Findley y otros, 2019: 32). Por otro lado, el monitor debe hablar con la comunidad para conocer su punto de vista sobre los protocolos, procedimientos o entrenamientos que recibe la policía.

Por último, existen importantes medidas para asegurar transparencia y publicidad. El monitor debe generar anualmente un reporte en el que informe el trabajo realizado por la IMO en el período, informar las tendencias identificadas en los reclamos, investigaciones y sanciones a los funcionarios de la policía en el período, identificar a funcionarios que han sido objeto de múltiples quejas, identificar reclamantes que han ingresado múltiples quejas y problemas generales que hayan sido denunciados. Asimismo, el reporte debe incluir recomendaciones sobre la suficiencia de las investigaciones

73. Los deberes de confidencialidad se extienden sobre todos los documentos e información sobre investigaciones o funcionarios involucrados, pero no alcanza a los que son necesarios para cumplir con otras obligaciones de transparencia. La confidencialidad es extensiva al staff del monitor, al COB y a todos los expertos contratados por el monitor.

74. En los casos de reclamos en contra del jefe u otro policía de alto rango, el monitor, en su discreción y de acuerdo con la capacidad de financiera de la oficina, puede nombrar a un investigador externo para dar más independencia al proceso. Lo mismo puede ocurrir cuando se solicite por el COB, el alcalde o el consejo municipal.

75. Para más información, véase el apartado «62.13 Police and fire departments», Wisconsin State Legislature, disponible en bit.ly/3ozk4Kd. El denominado Police and Fire Commission (PFC) es el organismo que aprueba las contrataciones, promociones y, en su caso, determina la imposición de sanciones, incluyendo suspensiones y despido. En particular, con respecto a los reclamos e investigaciones por mala conducta policial, es el órgano encargado de tomar la decisión final del caso ejerciendo funciones propias de un tribunal. 
y lo apropiado o inapropiado de las sanciones disciplinarias impuestas, cambios en protocolos, reglas y entrenamientos. ${ }^{76}$ Finalmente, debe incluirse una evaluación del progreso del MPD en dar cumplimiento a las normas, políticas y recomendaciones efectuadas (Findley y otros, 2019: 32).

Para construir el modelo híbrido, además de la Oficina del Monitor Independiente, la ciudad de Madison actualmente trabaja en la implementación de un COB. Se trata de una entidad que debe representar a la comunidad en toda su diversidad. Para asegurar esto, entre los criterios de nombramiento se incluyen raza, etnia, género, orientación sexual, región geográfica dentro de la ciudad, situación socioeconómica y experiencia previa con el Departamento de Policías de Madison (Findley y otros, 2019: 30). ${ }^{77}$

Aunque para ser miembro del Comité no se requiere ninguna destreza o conocimiento especial, se espera que los miembros del COB participen en capacitaciones para desarrollar experticia. Para esto, los miembros deben recibir financiamiento con el objetivo de acceder y participar en las capacitaciones que necesiten. De ese modo, lo que se busca es que no existan barreras socioeconómicas que impidan que los ciudadanos presten sus servicios en el COB, lo que debe ser asegurado por las autoridades de la ciudad, por ejemplo, a través del pago de estipendios, asegurando el cuidado de hijos, alternando horario de reuniones, entre otras medidas (Findley y otros, 2019: 33).

La función principal del COB es determinar si la Oficina del Monitor Independiente está cumpliendo con sus funciones de manera efectiva. Para llevar adelante sus funciones, el $\mathrm{COB}$ debe recibir de manera regular reportes del monitor, así como también debe tener acceso a ciertos archivos relevantes dentro del departamento de policía. El $\mathrm{COB}$ tiene la facultad de evaluar anualmente el desempeño del jefe de la policía a través de los reportes e información que reciba de parte del monitor. Por otro lado, aunque no directamente, tiene la facultad de evaluar la efectividad del monitor independiente mediante la entrega de información relevante a las autoridades de la ciudad, quienes tienen la última palabra en la evaluación de la IMO (Findley y otros, 2019: 32-33).

Asimismo, es función del COB hacer recomendaciones en diferentes áreas. Por ejemplo, pueden hacer recomendaciones con respecto a medidas disciplinarias, protocolos del uso de la fuerza, reglamentos internos de la policía, contratación, entrenamiento, relaciones de la policía con la comunidad y sobre el procedimiento de reclamo. Además, debe hacerse cargo de cualquier otro problema o inquietud que surja de la comunidad, de los miembros del COB, del monitor, del jefe de la policía o de las autoridades de la ciudad (Findley y otros, 2019: 32-33).

76. Asimismo, se establece la obligación de mantener constantemente disponible para el público un reporte de estado continuo con los mismos aspectos que deben ser informados en el reporte anual.

77. Bajo esta última fórmula se incluyen personas que hayan sido arrestadas, condenadas, sin hogar, con consumos problemáticos de alcohol y drogas o con problemas de salud mental. La razón es que estas personas pueden entregar información de primera fuente con respecto a los contactos e interacciones que han tenido con la policía de la ciudad. Este punto fue uno de los más cuestionados por la Policía de Madison durante el debate con respecto a la implementación de civilian oversight. 
Finalmente, el COB debe proporcionar un informe anual a las autoridades de la ciudad, en el cual el Comité evalúe el trabajo del monitor independiente, se señalen las actividades realizadas por el Comité, las preocupaciones expresadas por miembros de la comunidad, la evaluación del Comité sobre los procesos investigativos y disciplinarios de la policía, y las demás recomendaciones detalladas en el párrafo anterior (Findley y otros, 2019: 33).

\section{Conclusión}

Este documento introdujo el concepto de civilian oversight o supervisión civil, entendido como un mecanismo externo de responsabilización policial que, en cualquiera de sus formas, encarga a la ciudadanía el rol de llamar a las policías a rendir cuentas para hacer frente a determinados problemas que puedan enfrentar los departamentos. Estos están principalmente vinculados a la falta de legitimidad y a la pérdida de confianza y satisfacción por parte de la ciudadanía. Para ilustrar lo anterior, se presentaron los principales escenarios que han llevado a la adopción de este tipo de mecanismos, para luego presentar los principales modelos existentes en Estados Unidos. Por último, cada uno de estos modelos fue ejemplificado mediante la descripción de las principales características de entidades de supervisión específicas.

Desde el punto de vista del accountability policial, la supervisión civil debiese ser un tema relevante para cualquier sociedad democrática por los valores y principios que estas instituciones representan, especialmente en las sociedades en que sus policías enfrentan profundas crisis. En efecto, la supervisión civil es una alternativa legítima que puede entregar herramientas relevantes para hacer frente a dichos problemas, mejorando no solo las relaciones entre la policía y la comunidad, sino también el desempeño en la función policial detectando y resolviendo un amplio rango de problemas dentro de dichas instituciones que, en general, se traducen en una rendición de cuentas más efectiva hacia la comunidad.

Aunque existen diferencias organizacionales, culturales y de regulación legal entre las policías de Estados Unidos y Chile, es importante mirar este tipo de alternativas para mejorar los sistemas de responsabilización de las policías en el marco de la tan esperada reforma policial en Chile. En ese sentido, el contexto que se vive nos pone en el escenario ideal que históricamente ha llevado a la implementación de este tipo de soluciones. Sin embargo, también se debe considerar que no existe evidencia de que la supervisión civil pueda ser trasplantada - sin mas- a otras sociedades, aunque hay buenas razones para pensar que esto funcionaría, por los valores democráticos detrás de estos mecanismos y su compatibilidad con los principios que representan las sociedades democráticas modernas. Desde luego, no existe un modelo de talla única, sino que estos se deben construir de acuerdo con cada realidad y las necesidades específicas que se buscan resolver con especial consideración a las tensiones políticas, sociales y culturales que puedan existir. 


\section{Referencias}

Atlanta Citizen Review Board (2019). Annual Report 2019. Disponible en bit. ly/34Fip7N.

ATtARD, Barbara y Kathryn Olson (2013). «Overview of Civilian Oversight of Law Enforcement in the United States». Disponible en bit.ly/31Vqp92.

Beltrán, Víctor (2018). «¿Existen barreras de acceso al procedimiento de reclamos por controles preventivos de identidad abusivos o denigratorios?: Una investigación exploratoria». Disponible en bit.ly/3kVEafa.

Воттомs, Anthony y Justice Tankebe (2012). «Beyond Procedural Justice: A dialogic Approach to Legitimacy in Criminal Justice». Journal of Criminal Law and Crimino$\log y, 102$ (1): 119-170. Disponible en bit.ly/31UYIo2.

BRodeUr, Jean-Paul (1999). "Accountability, the search for a Theoretical Framework». En Errol Mendez (editor), Democratic Policing and Accountability: Global perspectives. Aldershot, Vermont: Ashgate.

Centro de Estudios Públicos (2019). Estudio nacional de opinión pública 84. Santiago: CEP. Disponible en bit.ly/37XKsYm.

City of Urbana Civilian Police Review Board (2012). Policy and Procedure ManUal. Disponible en BIT.LY/31YBhCX.

Clarke, Stephen (2009). «Arrested oversight: A comparative Analysis and Case Study of How Civilian Oversight of the Police Should function and How it Fails». Columbia Journal of Law and Social Problems, 43 (1): 1-49. Disponible en bit.ly/2HJwlLc.

Comisión para la Reforma (2020). Propuesta de Reforma a Carabineros de Chile. Disponible en bit.ly/34EUTxL.

Contreras, Pablo, Ricardo Montero y Sebastián Salazar (2020). ««Obedientes y no delbierantes»: Fuerzas Armadas, autonomía y control democrático en Chile». Ius et Praxis, 26 (2): 232-253. Disponible en bit.ly/3e8nxul.

DAmmert, Lucía (2020). «Carabineros de Chile: ¿El modelo latinoamericano de deguridad?». Análisis Carolina. Disponible en bit.ly/3jzUkJW.

De Angelis, Joseph, Richard Rosenthal y Brian Buchner (2016). Civilian Oversight of Law Enforcement: A Review of the Strengths and Weaknesses of Various Models. Washington D.C.: Office of Justice Programs.

-. (2016a). Civilian Oversight of Law Enforcement: Assessing the Evidence. Washington D.C.: Office of Justice Programs.

Dempsey, John y Linda Forst (2013). An Introduction to Policing. 7. ed. Boston: CENGAGE Learning.

Duce, Mauricio y Lucía Dammert (2019). «Propuestas para iniciar un proceso de reforma a Carabineros de Chile». Fundación Espacio Público. Disponible en bit. ly/3jEcESg.

FindLEY, Keith, Gregory Gelembiuk, Tom Brown, Matthew Braunginn, Verónica Figueroa, Jacquelyn Hunt Kim Jorgensen, Linda Ketchum, Sue Petkovsek, Sean Saiz, Mario García Sierra y Luis Yudice (2019). Madison Police Department Policy 
and Procedure Review Ad Hoc Committee Final Report. Disponible en https://bit. ly/3mA2rIb.

FinN, Peter (2001). Citizen Review of Police: Approaches and Implementation. NIJ Issues and Practices in Criminal Justice. Washington D.C.: US Department of Justice.

FrüHling, Hugo (2003). Policía comunitaria y reforma policial en América Latina ¿Cuál es el impacto? Santiago: Instituto de Asuntos Públicos de la Universidad de Chile.

Fundación Paz Ciudadana (2019). Índice Paz Ciudadana. Resultados del año 2019. DisPonible EN BIT.LY/2HSXP61.

Goldsmith, Andrew y Collen Lewis (2000). Civilian Oversight of Policing: Governance, Democracy and Human Rights. Oxford: Hart.

Goldstein, Herman (1977). Policing in a Free Society. Cambridge, Massachusetts: Ballinger Publishing.

Hryniewicz, Danielle (2011). "Civilian oversight as a public good: democratic policing, civilian oversight, and the social». Contemporary Justice Review 14 (1): 77-83. Disponible en bit.ly/3jHvB6y.

KING, Kevin (2015). «Effectively Implementing Civilian Oversight Boards to Ensure Police Accountability and Strengthen Police-Community Relations». Hastings Race \& Poverty Law Journal, 12: 91-120. Disponible en bit.ly/31X09Ov.

MaWby, Robert y Alan Wright (2005): «Accountability Policial: $¿$ Es bueno para el resto del mundo lo que es bueno para Occidente?». Estudios Sociológicos 21 (60): 902-912. Disponible en bit.ly/37SKvEF.

Mazerrolle, Lorraine (2020). «Herman Goldstein (1931-2020): A tribute». Policing and Society, 30 (3), 349-354. Disponible en bit.ly/31U9JPf.

Miller, Joel (2002). Civilian Oversight of Policing. Lessons from Literature. Nueva York: Vera Institute of Justice.

Mitchell, Nicholas (2019). «2019 Annual Report». Denver. Office of the Independent Monitor. Disponible en bit.ly/2TzHror.

Mugari, Ishmael (2018). «Rethinking the Models of Police Oversight: Toward a New Paradigm». En Ali Farazmand (editor), Global Encyclopedia of Public Administration, Public Policy, and Governance. Cham: Springer. Disponible en bit.ly/366ZhVW.

MurPhy, Kristina, Lyn Hinds y Jenny Fleming (2008). «Encouraging public cooperation and support for police». Policing and Society, 12 (2): 136-155. Disponible en bit. ly/3mB6Bjo.

OIR Group (2017). CiviLIAN Oversight of LAW ENFORCEMENT: How it Works, Why it Matters. Disponible en bit.ly/35M7cYB.

Phillips, Emma y Jennifer Trone (2002). Building Public Confidence in Police Through Civilian Oversight. Nueva York: Vera Institute of Justice.

Police Assessment Resource Center (2005). Review of National Police Oversight Models for the Eugene Police Commission. Los Ángeles: Police Assessment Resource Center. Disponible en bit.ly/3kE1A8V.

-. (2016). Peer Review of the New Orleans Office of Independent Police Monitor. Los Ángeles: Police Assessment Resource Center. Disponible en bit.ly/3jLRwcC. 
Porter, Louise y Tim Prenzel (2015). «Complainant's views of police complaint system. The gap between aspiration and experience». En Prenzel, Tim y Garth Den Heyer (editores), Civilian Oversight of Police. Advancing Accountability in Law Enforcement. Boca Raton, Florida: CRC Press.

President's Task Force on 21st Century Policing (2015). Final Report of the President's Task Force on 21st Century Policing. Washington, D.C.: Office of Community Oriented Policing Services. Disponible en bit.ly/35M8zXf.

Reiner, Robert (1993). «Police Accountability: Principles, Patterns and Practices». En Robert Reiner y Sarah Spencer (editores), Accountable policing: Effectiveness, Empowerment and Equity. Londres: Institute for Public Policy Research.

RoAcH, Kent (2014). "Models of civilian Police Review: The Objectives and Mechanisms of Legal and Political Regulation of the Police». Criminal Law Quarterly, 61: 29-73. Disponible en bit.ly/2HNCHca.

Schedler, Andreas (1999). "Conceptualizing accountability». En Andreas Schedler, Larry Diamon y Marc Plattner (editores), The Self-Restraining State: Power and Accountability in New Democracies. Boulder, Colorado: Lynne Rienner Publishers.

SEN, Sankar (2010). Enforcing Police Accountability Through Civilian Oversight. Nueva Delhi: Sage.

Stephens, Darrel, Ellen Scrivner y Josie Cambareri (2018). Civilian Oversight of the Police in Major Cities. Washington D.C.: Office of Community Oriented Policing Services.

Stone, Christopher y Merrick Bobb (2002). Civilian Oversight of the Police in Democratic Societies. Nueva York: Vera Institute of Justice.

United Nations Office on Drugs and Crime (2011). Handbook on Police Accountability, Oversight and Integrity. Nueva York: United Nations. Disponible en bit. ly/3jQZgih.

Walker, Samuel (2001). Police Accountability: The Role of Citizen Oversight. Belmont, California: Wadsworth.

-. (2006) «The History of Citizen Oversight». En Justina Perino (editor), Citizen Oversight of Law Enforcement. Chicago: ABA Publishing.

Walker, Samuel y Carol Archbold (2014). The New World of Police Accountability. 2. ${ }^{\mathrm{a}}$ ed. Los Ángeles: Sage Publications.

\section{Agradecimientos}

Esta publicación se basa fundamentalmente en un capítulo de una investigación independiente desarrollada por el autor durante los meses de enero a mayo de 2020 en la Universidad de Wisconsin-Madison. Para el desarrollo de esta investigación y para la producción de este trabajo, el autor no recibió financiamiento alguno. La investigación basal de este trabajo se enfocó, principalmente, en la creación e implementación del mecanismo de supervisión civil de la ciudad de Madison y fue guiada por el profesor Keith Findley, a quien el autor manifiesta sus más sinceros agradecimientos y admira- 
ción. Además, el autor agradece los valiosos comentarios de quienes hicieran la revisión anónima de este manuscrito. Naturalmente, cualquier error que subsista es de mi exclusiva responsabilidad.

\section{Sobre el autor}

Víctor Beltrán Román es abogado y licenciado en Ciencias Jurídicas y Sociales por la Universidad Diego Portales. Además, es Master of Laws (LL.M.) Legal Institutions de la Universidad de Wisconsin-Madison. Su correo electrónico es beltranroman@wisc. edu. (D) https://orcid.org/0000-0003-3554-1838. 
La Revista de Derecho Público es publicada desde 1963 por el Departamento de Derecho Público de la Facultad de Derecho de la Universidad de Chile. Aparece dos veces al año. Su propósito es la difusión de los avances del derecho público nacional e internacional y la socialización de artículos de investigación inéditos de la comunidad académica nacional e internacional.

DIRECTORA

Ana María García Barzelatto

SECRETARIO DE REDACCIÓN

Felipe Peroti Díaz

fperoti@derecho.uchile.cl

SITIO WEB

revistaderechopublico.uchile.cl

CORREO ELECTRÓNICO

publico@derecho.uchile.cl

LICENCIA DE ESTE ARTÍCULO

Creative Commons Atribución Compartir Igual 4.o Internacional

La edición de textos, el diseño editorial

y la conversión a formatos electrónicos de este artículo

estuvieron a cargo de Tipográfica

www.tipografica.io 